\title{
Honeybee workers with higher reproductive potential have a greater learning ability
}

\author{
Karolina KuszewsKa (D), Wiktoria RoJeK \\ Institute of Environmental Sciences, Jagiellonian University, Krakow, Poland \\ Received 27 July 2020 - Revised 2 January 2021 - Accepted 4 February 2021
}

\begin{abstract}
Learning ability, which allows individuals to adjust their behaviour to changing environmental conditions, has a considerable positive impact on individual fitness. However, in addition to benefits, learning also incurs a cost, which means that investment in learning and maintaining learned skills can lead to trade-offs impacting other biological functions. Here, we tested whether a trade-off exists between learning skills and reproductive potential in honeybee workers. For this purpose, we compared learning ability between two groups of workers that differed in reproductive potential - normal and rebel workers. The results showed that workers with high reproductive potential (rebels), measured according to the number of ovarioles in the ovary, learned faster than normal workers with low reproductive potential. Moreover, by performing separate regression analyses within the rebel and non-rebel worker groups, we found that the reproductive potential of workers was positively correlated with their learning ability. The results show that in honeybees, there is no trade-off in resource allocation between two costly biological functions, learning and reproduction.
\end{abstract}

\section{Apis mellifera / honeybee / rebel workers / learning / evolutionary trade-off / reproduction}

\section{INTRODUCTION}

Learning ability, defined as the acquisition and storage of neuronal representations of information through experience, is exhibited by many animals (Thompson 1986). Learning allows individuals to adjust their behaviours according to changing environmental conditions (Dukas 2008), which can have considerable positive impacts on individual fitness components. Despite the benefits of learning, this process, similar to other biological processes, requires energy and is costly (Mery and Kawecki 2004, 2005; Snell-Rood et al. 2009). Therefore, investment in learning and the maintenance of learning skills can result in trade-offs with investments in other biological functions. Previous studies have confirmed this expectation

Corresponding author: K. Kuszewska,

k.kuszewska@uj.edu.pl

Handling Editor: David Tarpy and showed that in some species, the ability to learn is associated with delayed reproduction (Mery and Kawecki 2003, 2004, 2005; SnellRood et al. 2011). This phenomenon occurs because resources that might be invested in reproductive tissue are redirected to development and maintenance of energetically expensive neural tissue, which is required for learning and memory (Laughlin et al. 1998).

Despite interest in the trade-offs between learning ability and other life-history traits in animals, our understanding of this process is still incomplete. Most studies on the costs and benefits of trade-offs associated with learning have focused on fruit flies (Drosophila melanogaster) (Mery and Kawecki 2003, 2004). Fruit flies from outbred lines selected for high learning ability learned the aversive smell and taste of ovipositional substrate faster than fruit flies originating from a line selected for low learning ability; however, the highlearning ability flies laid fewer eggs in total 
(Mery and Kawecki 2004), and their larvae showed weaker competitive ability than those of the low-learning ability flies (Mery and Kawecki 2003). Other studies also showed that fruit flies incur other costs associated with long-term memory, with trained flies dying earlier in stressful environments (without food and water) than control individuals (Mery and Kawecki 2005). Studies that have evaluated trade-offs between learning ability and other life functions are not limited to fruit flies. Negative correlations between learning ability and trade-offs were found in butterflies (Pieris rapae) (Snell-Rood et al. 2011), antlion (Myrmeleon bore) larvae (Miler et al. 2018b) and predatory mites (Phytoseiidae) (Christiansen et al. 2016).

Learning ability is considered to play a key role in the success of social insects, such as ants (Paul et al. 2010) and honeybees (Menzel and Muller 1996). Societal life has promoted the evolution of different types of learning and communication among colony members. Extensive research, especially on bumble bees (Bombus spp.) and honeybees (Apis mellifera), has provided critical information about learning in these insects (Dukas 2008). It is well known that bees can learn spatial information necessary for foraging (Winston 1987) and how to efficiently collect resources from certain flowers, but they can also learn from other individuals, which is important because it allows the fast dissemination of novel behaviours among colony members (Leadbeater and Chittka 2007; Leadbeater and Dawson 2017). Although many studies on learning in honeybees and bumblebees have been conducted, the trade-offs that exist between learning ability and other biological functions remain unclear. Previous studies found no trade-off between learning speed and associative flexibility (Raine and Chittka 2012) or between colony learning performance and immune response in bumblebees (Alghamdi et al. 2009). Similarly, in honeybees, there is no evolutionary trade-off between associative learning and metabolic stress resilience (Amdam et al. 2010). However, learning was found to be energetically costly, and individuals that are exposed to energetic stress suffer from significant cognitive deficits (Jaumann et al. 2013). Overall, we know little about the trade-offs between learning ability and other life functions in bees. It should also be noted that almost all the previous studies that focused on trade-off between learning skills and the reproductive potential of individuals focused on solitary species, and the studies showed that the trade-off is mainly delayed reproduction (e.g. Mery and Kawecki 2003; Miler et al. 2018a). This situation is completely different in social insects, such as honeybees, as the most important decision is whether to lay eggs, not when to lay eggs. For this reason, it is possible that the trade-off between learning and reproduction in social insects is characterised by a different pattern than that in solitary insects.

Honeybee workers are usually sterile because pheromones from the queen efficiently inhibit the development of ovaries in workers (Winston 1987). However, under certain conditions, honeybee workers can activate their ovaries and lay unfertilised eggs that develop into males (drones). This usually occurs when the colony is queenless (Winston 1987) because the absence of queen pheromones in a nest stimulates ovary activation and hinders the normal policing mechanisms that prevent workers from laying eggs (Ratnieks and Visscher 1989; Woyciechowski and Lomnicki 1987). It is well known that not all workers have the same opportunity for ovary activation, as such activation is dependent on the reproductive potential of individuals, which can be easily measured according to the number of ovarioles in the ovaries (Makert et al. 2006). The number of ovarioles is determined during larval development and depends on the quality and quantity of food (Winston 1987), the presence of a queen (M Woyciechowski and Kuszewska 2012) and the production of mandibular gland pheromones (Michal Woyciechowski et al. 2017). Moreover, a recent study showed that honeybee workers that develop in a queenless nest as larvae become relatively selfish individuals with higher reproductive potential than those that develop in a nest with a queen (Karolina Kuszewska and Woyciechowski 2015; M Woyciechowski and Kuszewska 2012). These workers are called rebel workers (M Woyciechowski and Kuszewska 2012), and studies have shown that these individuals lay eggs more often than normal workers, even if they remain in a colony with a queen 
(Karolina Kuszewska et al. 2018c). Compared to normal workers, rebel workers are characterised not only by their increased reproductive potential but also by their prolonged life (Karolina Kuszewska et al. 2017), different foraging preferences (Kuszewska et al. 2018b), tendency to drift to other colonies (Karolina Kuszewska et al. 2018a) and increased sucrose sensitivity (Karolina Kuszewska et al. 2019).

Because rebel workers differ from typical workers in their physiology, including their reproductive potential and behaviour, we believe that they are an excellent model for testing the hypothesis that there is trade-off between reproductive potential and learning ability in bees. Therefore, in this paper, we compared these two parameters between normal and rebel workers. In addition, we separately evaluated whether learning ability is dependent on reproductive potential within the two groups of workers, namely, normal and rebel workers.

\section{MATERIALS AND METHODS}

We performed experiments in May and June of 2018 in an experimental apiary at the Institute of Environmental Sciences of Jagiellonian University. We used four queenright colonies (A. mellifera), each consisting of 20,000-40,000 workers. The colonies were randomly chosen for the experiments, and their queens were not related to one another and were naturally inseminated during nuptial flight. There was no breeding programme for any selected line in this experimental apiary. All colonies were treated in the same way. The experimental design has been previously described by Woyciechowski and Kuszewska (2012) as well as others (i.e., Kuszewska et al. 2017, 2018b; Woyciechowski et al. 2017). At the beginning of the experiment, the queen was restricted to two experimental frames to produce eggs of a similar age (day 0 ). Next, the colony was divided into queenright (with the original laying queen) and queenless subunits, and each subunit was contained within one experimental frame (day 3). When all of the worker cells in the experimental frames were sealed (day 12), the subunits were merged, and subsequently, the experimental broods experienced the same conditions during the prepupal and pupal stages. Before the first adult workers emerged (day 21), all the experimental frames were placed in an incubator in the laboratory $\left(34{ }^{\circ} \mathrm{C}, 90 \%\right.$ relative humidity $\left.(\mathrm{RH})\right)$. The workers were marked on the thorax with a spot of paint (Marabu-Brilliant Painter, 200 from each group and colony) and returned to their native colonies. When the marked workers were 21 days old, 50 workers from each group (reared as larvae in the queenright and queenless subunits) were removed. The removed workers were subject to an experiment that tested their learning abilities.

The bees (50 from each group) were individually harnessed in a plastic tube (conditioning station) and secured to achieve immobility for the proboscis extension reflex (PER) learning procedure (Martin Giurfa and Sandoz 2012). Next, the subjects were fed $10 \mu \mathrm{l}$ of a $50 \%$ sucrose solution within $30 \mathrm{~min}$ of being restrained and then left alone for $2 \mathrm{~h}$ in the dark (resting phase). The bees that were harmed or died as a result of their attachment to the plastic tube (conditioning station) were removed. Subsequently, all individuals that were still alive (number of bees used in the learning test per group: colony 1 -normal workers $=44$, rebel workers $=42$; colony 2 -normal workers $=42$, rebel workers $=45$; colony 3 -normal workers $=43$, rebel workers $=$ 41 ; colony 4-normal workers $=43$, rebel workers $=42$ ) were conditioned with an odour (1-hexanol, 99.8\% purity; Sigma-Aldrich) presented before a reward consisting of a food solution (CS+, 50\% sucrose). After allowing $10 \mathrm{~s}$ for placement in the experimental setup, the odours were presented for $5 \mathrm{~s}$. Three seconds after the onset of the odour, the rewards were supplied for $4 \mathrm{~s}$. Five seconds after the rewards were removed, the bees were removed from the experimental setup (Giurfa and Sandoz 2012; Ricarda Scheiner et al. 2013). When an individual showed the PER after the cue in two consecutive trials, it was recorded as having learned the signal. The interval between learning trials was $10 \mathrm{~min}$. After completion of the trials, all tested bees were frozen pending organ dissection.

We dissected the ovaries of the frozen workers and examined them under a stereomicroscope. We counted the number of ovarioles in both 
ovaries (sum) and evaluated ovary development. To assess ovarian development, the most developed ovariole in each of the ovaries was selected, and the maximum diameter of these two ovarioles (maximum width) was measured. The wider ovariole was used in the analysis, as described by Nakaoka et al. (2008), who found that ovariole diameter accurately reflects ovarian activity. All organs were stained with Giemsa reagent for approximately $10 \mathrm{~s}$ before being measured.

Mixed-model two-way ANOVA was used to compare ovariole number between rebel and normal workers, with the experimental group (reared in queenright or queenless conditions) as a fixed effect and colony as a random effect. To compare the learning abilities of the normal and rebel workers, measured as the number of workers that reacted to the cue with PER, the G-test with Williams' correction was used. Associations between the reproductive potential (number of ovarioles) and learning ability of bees as well as reproductive potential (number of ovarioles) and ovary activation (development) were compared using separate simple regressions for rebel and normal workers and for all colonies (eight analyses in total for learning ability and eight analyses in total for ovary activation). All calculations were conducted in STATISTICA 13.1.

\section{RESULTS}

Similar to those in previous studies, the results showed that 15-day-old workers reared as larvae under queenless conditions (rebel workers) had significantly more ovarioles than did workers of the same age reared under queenright conditions (normal workers; mixed-model two-way ANOVA; $F_{1,3}=455.73, P<0.001$; Figure 1 ). The learning ability test also showed that rebel workers learned faster than normal workers. The results were statistically significant for the bees originating from all four colonies (G-test: colony $1-d f=3, G=17.56, P<0.001$; colony $2-d f=$ $3, G=11.75, P=0.008$; colony $3-d f=3, G=$ 20.46, $P<0.001$; colony $4-d f=3, G=9.46, P$ $<0.024$; Figure 2).

The simple regressions showed that workers with a high number of ovarioles learned faster (or, in other words, finished learning earlier in the training trials) than those with a lower number both in the normal and rebel worker groups (Table I and Figure 3). Similarly, the results showed that in both groups (normal and rebel workers), the number of ovarioles was positively correlated with ovary activation (Table II and Figure 3).

\section{DISCUSSION}

Both learning and reproduction are costly, which means that individuals should allocate available resources during their development to learning ability and future reproduction (reproductive potential). The results of previous studies seem to confirm these assumptions because, in fruit flies (Mery and Kawecki 2003) and in butterflies (Pieris rapae) (Snell-Rood et al. 2011), fecundity is negatively associated with learning. In the present study, we examined the potential trade-offs between rapid learning and reproductive potential in two groups of honeybee workers, namely, normal and rebel workers, from the same colonies. In contrast to the previous studies, our data showed that rebel workers, characterised by higher reproductive potential, learned faster than normal workers with lower reproductive potential (Figure 2). Moreover, by performing tests in each group separately, we also found that the reproductive potential of workers was positively correlated with learning ability (Figure 3). Therefore, potential trade-offs between learning and reproductive potential do not exist in honeybees. These results are surprising, especially because it is well known that honeybee workers pay a significant energetic cost for learning and suffer learning and retention deficits when they are energetically stressed (Jaumann et al. 2013). Notably, in our study, we tested learning ability in individuals that had not been subjected to energetic stress in the adult stage, and the workers from both groups had enough food. Those that did not have enough food were removed from the experiment, which is standard in PER-based studies. The potential differences in resource allocation between learning ability and reproductive potential were limited to the open larval stage. It is possible that some larvae were fed food of better quality and quantity and could therefore invest in both future learning and 


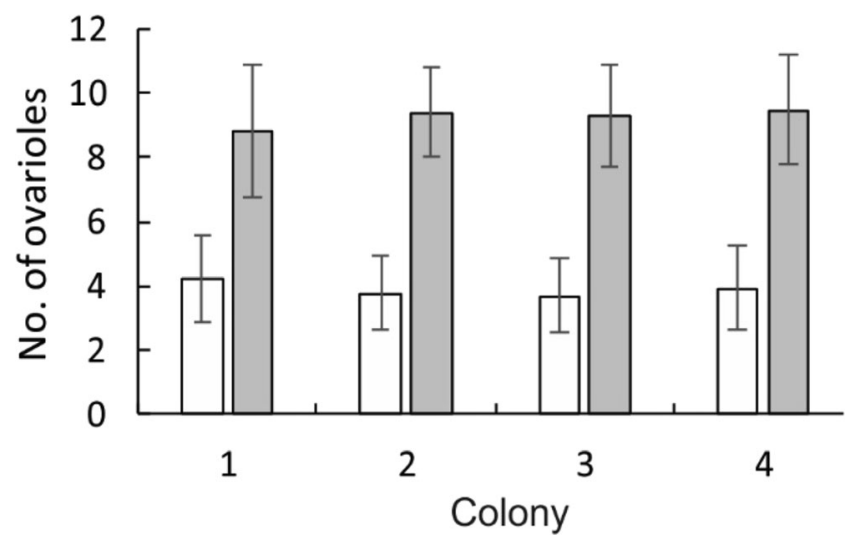

Figure 1. Number of ovarioles (mean $\pm \mathrm{SD}$ ) in honeybee workers reared under queenright (normal workers; empty bars) and queenless conditions (rebel workers; grey bars).

reproduction. Differences in how female larvae in honeybee colonies are fed is not surprising, and such differences are usually imposed to rear the different female castes (Winston 1987). It is well known that larvae fed food of good quality and quantity develop into queens, while those provided with food of poor quality and quantity develop into workers (Winston 1987). Moreover, another study showed that larvae that remain in queenless nests, which also results in rebel worker development, obtain more food than those that develop in the queenright condition (Woyke 1999). Therefore, we believe that even if all larvae are reared under the same conditions in the nest, they can be fed slightly different foods, which causes them to invest a potential surplus of resources into both learning ability and reproduction. This situation is possible and was previously described in Daphnia sp. as a phenomenon called 'big houses, big cars', where some individuals will have more resources to allocate to all aspects of their life history (Reznick et al. 2000). However, a positive association between the reproductive potential of a worker and its learning skills was found not only for workers from two different groups, where the larvae could obtain different qualities and quantities of food, but also for workers in each group, where the larvae were fed similar foods. This result indicates that there is no trade-off between these two biological functions in honeybee workers. Previous studies showed that rebel workers were less sensitive than normal workers to the sucrose concentration in solutions and did not respond to a solution with a low sugar concentration (Karolina Kuszewska et al. 2019). The difference in sucrose sensitivity between these two groups of workers can influence the speed of learning. It is well known that if animals cannot recognise rewards or punishment, they also cannot learn to associate signal and experience (reward or punishment) (Ricarda Scheiner et al. 2013). However, in our study, we used a high concentration of sugar in the solution $(50 \%)$, to which almost all individuals reacted (in both groups), which means that the reward was recognised by both normal and rebel workers. Moreover, if a difference in sensitivity to sugar concentration between normal and rebel workers influenced the results of this study, we would expect the rebel workers to learn more slowly than normal workers because they would be less sensitive to the sucrose solution. It means that despite their lower sucrose sensitivity, the rebel workers learned faster than the normal workers.

Rebel workers differ from normal workers not only in reproductive potential but also in behaviour. Rebel workers usually remain in the hive for a longer period of time before the onset of foraging (Kuszewska et al. 2018a, b, c) and prefer to collect more nectar, as opposed to pollen, than normal workers (Kuszewska et al. 2018a, b, c). Moreover, a recent study showed that rebel 


\section{Colony 1}

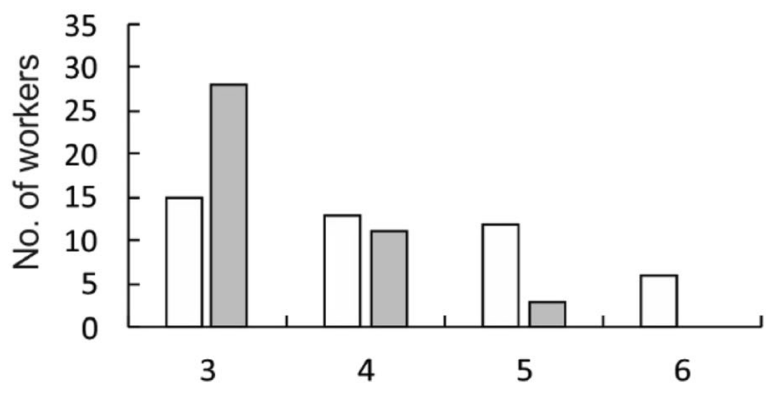

Colony 2

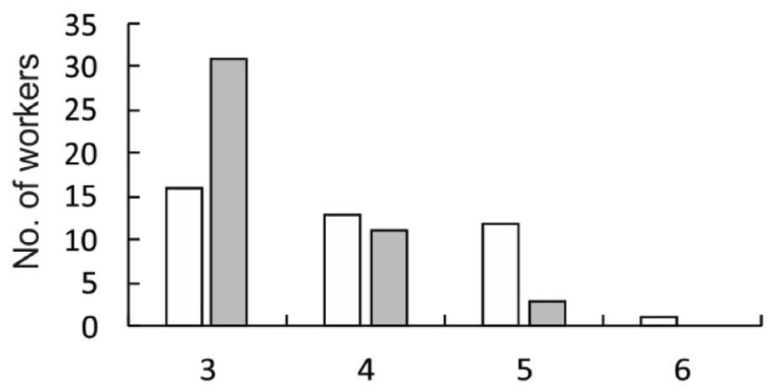

Colony 3

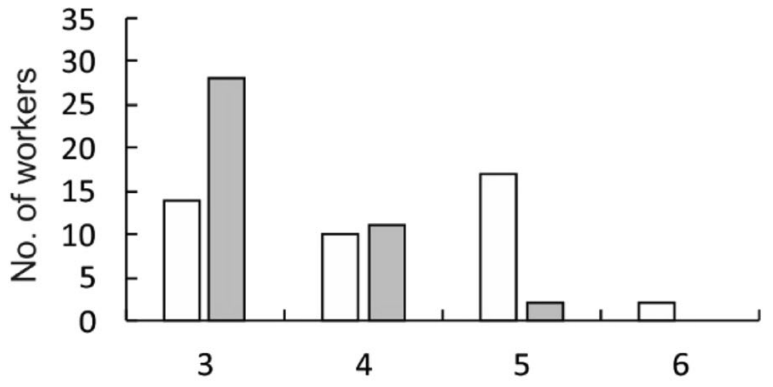

Colony 4

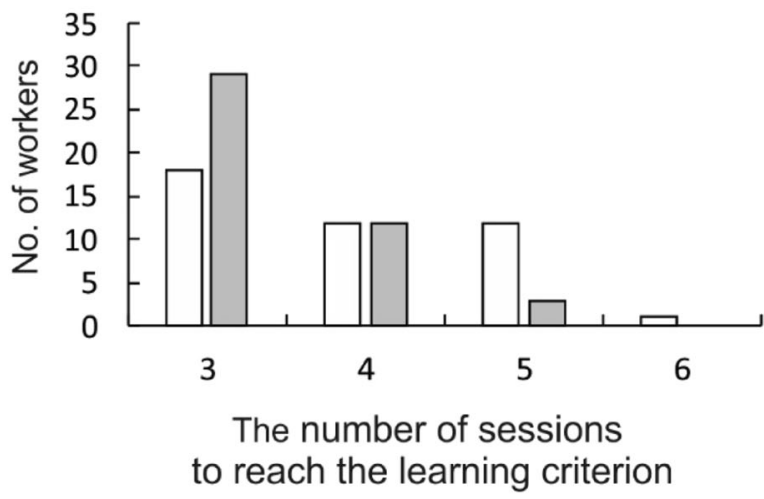

Figure 2. Numbers of normal workers (empty bars) and rebel workers (grey bars) reaching the learning criterion (two consecutive reactions to the cue) across different numbers of sessions. 
Table I. The results of simple regression analyses comparing the number of ovarioles and number of sessions necessary to fulfil the learning criterion

\begin{tabular}{lllllc}
\hline & & $\boldsymbol{\beta}$ & $\boldsymbol{R}^{\mathbf{2}}$ & $\boldsymbol{F}$ & $\boldsymbol{P}$ \\
\hline Colony 1 & Normal workers & -0.776 & 0.591 & $F_{1,42}=63.390$ & $<0.001$ \\
& Rebel workers & -0.667 & 0.431 & $F_{1,40}=32.014$ & $<0.001$ \\
Colony 2 & Normal workers & -0.679 & 0.448 & $F_{1,40}=34.310$ & $<0.001$ \\
& Rebel workers & -0.545 & 0.281 & $F_{1,43}=18.206$ & $<0.001$ \\
Colony 3 & Normal workers & -0.686 & 0.457 & $F_{1,41}=36.429$ & $<0.001$ \\
& Rebel workers & -0.489 & 0.220 & $F_{1,39}=12.284$ & 0.001 \\
Colony 4 & Normal workers & -0.580 & 0.320 & $F_{1,41}=20.741$ & $<0.001$ \\
& Rebel workers & -0.666 & 0.429 & $F_{1,40}=41.849$ & $<0.001$ \\
\hline
\end{tabular}

workers also drifted to other colonies more frequently than normal workers, especially queenless colonies where they fully activated their ovaries (with eggs inside), proving that they lay their own eggs (Kuszewska et al. 2018a, b). The frequent drifting by rebel workers to foreign colonies can be explained by perception mistakes and orientation failures, or as suggested by the authors of previous papers, by the reproductive parasite strategy of rebel workers (Kuszewska et al. 2018a, b). The results of our study, which showed that rebel workers learned faster than normal workers, rejected the explanation that rebel workers lost their way back to their own hive and supported the theory that these individuals intentionally drift to foreign colonies.

Our results showed that the reproductive potential of workers, measured by the number of ovarioles in the ovaries, was positively correlated with both ovary activation and the speed of learning (Figure 3). It would be interesting to consider how learning ability and reproductive potential are associated at the biochemical level. The substance responsible for the association between reproduction and learning ability is most likely dopamine (DA), which is a biogenic amine that was first identified in the central nervous system of animals (Carlsson et al. 1958). Subsequent
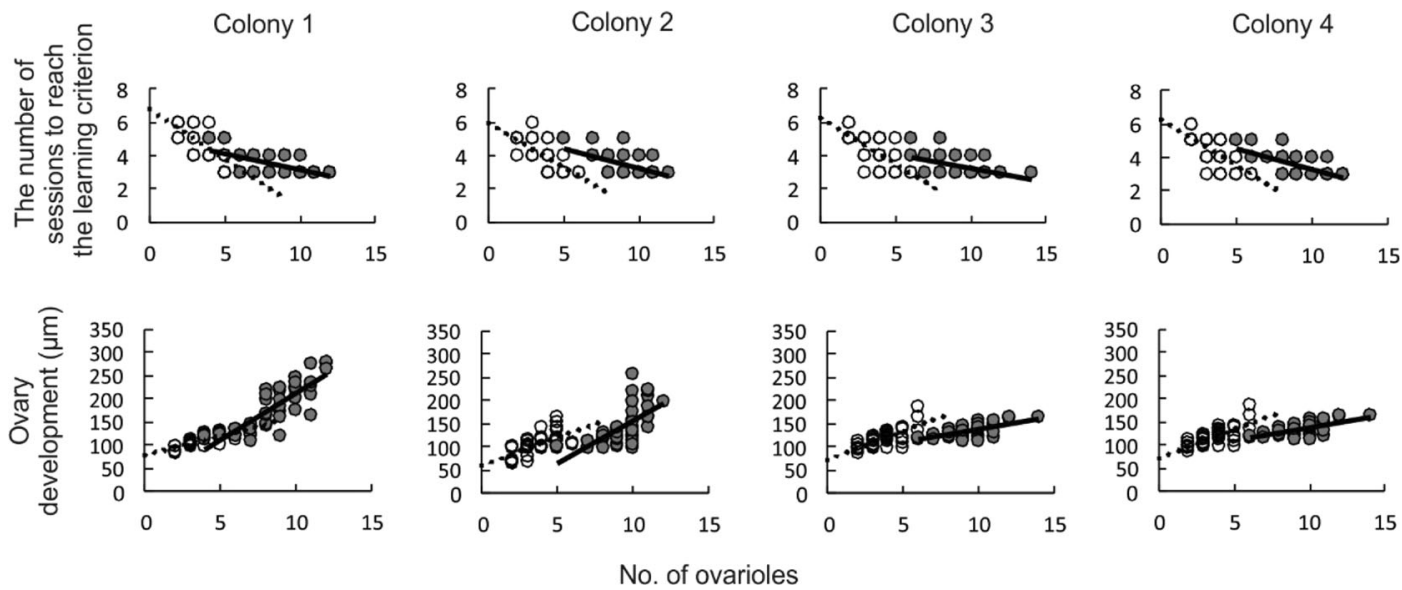

No. of ovarioles

Figure 3. The correlation between the number of ovarioles and other parameters (the number of sessions necessary to reach the learning criterion and ovary development in $\mu \mathrm{m}$ ) for normal (empty circles and dotted lines) and rebel workers (grey circles and solid lines). The data are shown separately for each experimental colony. The lines indicate that parameters are related to the number of ovarioles. 
Table II. The results of simple regression analyses comparing the number of ovarioles and ovary development

\begin{tabular}{llllll}
\hline & & $\boldsymbol{\beta}$ & $\boldsymbol{R}^{\mathbf{2}}$ & $\boldsymbol{F}$ & $\boldsymbol{P}$ \\
\hline Colony 1 & Normal workers & -0.814 & 0.655 & $F_{1,42}=82.628$ & $<0.001$ \\
& Rebel workers & -0.829 & 0.680 & $F_{1,40}=88.066$ & $<0.001$ \\
Colony 2 & Normal workers & -0.607 & 0.353 & $F_{1,40}=23.394$ & $<0.001$ \\
& Rebel workers & -0.627 & 0.379 & $F_{1,43}=27.803$ & $<0.001$ \\
Colony 3 & Normal workers & -0.723 & 0.511 & $F_{1,41}=44.847$ & $<0.001$ \\
& Rebel workers & -0.656 & 0.415 & $F_{1,39}=29.420$ & $<0.001$ \\
Colony 4 & Normal workers & -0.697 & 0.474 & $F_{1,41}=38.840$ & $<0.001$ \\
& Rebel workers & -0.846 & 0.708 & $F_{1,40}=100.351$ & $<0.001$ \\
\hline
\end{tabular}

studies showed that DA plays a role in regulating the behaviour of animals, including reproduction, learning and locomotor activity (Beninger 1983). In honeybees, the level of DA in the brain changes with caste, and the level of DA in the brains of queens is higher than that in the brains of normal workers (Harano et al. 2005; Sasaki et al. 2012). The DA level is also associated with age-related tasks, which vary among workers. Foragers have higher brain DA levels than nurse bees, but pollen foragers have higher levels of DA than nectar foragers (Taylor et al. 1992). Other studies have also shown that the presence of queen pheromones modulates brain DA levels (Beggs et al. 2007) and that elevated brain DA levels in workers are positively correlated with worker ovary development (Harris and Woodring 1995). Moreover, in honeybees, DA also influences the modulation of motor aspects of learning and memory, and dopaminergic neuronal activity is necessary for associative learning, especially aversive learning (Agarwal et al. 2011; M Giurfa 2006; Vergoz et al. 2007). However, a recent study showed that DA can also mediate appetitive sucrose signalling and the association between colour and sucrose reward in the bee brain (Mancini et al. 2018). Another biochemical substance that also influences the learning ability in bees is octopamine (OA). OA is also a biogenic amine that is an important modulator of behaviour in vertebrates and invertebrates, including the honeybee (Scheiner et al. 2006). OA increases peripheral olfactory sensitivity in the honeybee (Spivak et al. 2003) and increases sensitivity to sucrose in honey bee foragers (Scheiner et al.
2002). It was also found that OA is important for associative appetitive learning in insects because it mediates the reward signal (Vergoz et al. 2007). However, we think that OA does not have much of an impact on the results of our study for two reasons. First, rebel workers, which learned faster, are less sensitive to sugar concentration than normal workers, which learned slower (Kuszewska et al. 2019). Second, in our study, we used 21day-old bees, all of which were foragers. There are studies that showed that OA improved learning performance in only newly emerged bees, while in old foragers, OA treatment slightly decreased the ability to learn (Behrends and Scheiner 2012).

All previous studies that focused on trade-offs between learning skills and the reproductive potential of individuals focused on solitary species (e.g., Mery and Kawecki 2003; Mery and Kawecki 2004; Mery and Kawecki 2005; SnellRood et al. 2011). However, the honeybee is a eusocial species, where individuals live together and the whole society is involved in the raising of the queen's offspring. Therefore, the biology of the honeybee is fundamentally different from that of solitary organisms. Some of the evolutionary trade-offs found in solitary species do not exist in social insects. In most animals, longevity is achieved at the expense of fertility, but queens of social insects do not show this trade-off (Keller and Genoud 1997; Parker 2010). The honeybee queen can live for 1 to 3 years despite her high metabolism and production of approximately 2000 eggs per day (Winston 1987). In contrast, workers, characterised by limited fecundity, live 
for 3-6 weeks in the middle of the season in temperate climates (Winston 1987). Differences in some biochemical parameters have been observed between solitary and social insects. In most insects, there is a positive correlation between juvenile hormone $(\mathrm{JH})$, a major insect hormone with diverse influences on growth, reproduction and longevity in many species, and the yolk precursor protein vitellogenin (Vg) (Swevers et al. 2005). In honeybees, however, these two substances are negatively correlated (Corona et al. 2007). Our results also showed that in the honeybee, a representative social insect, the trade-off between learning ability and reproductive potential is completely different from that observed in solitary animals.

In summary, we have shown that rebel workers not only have higher reproductive potential but also learn faster than normal workers. Moreover, the results revealed a positive association between reproductive potential and learning ability among workers from a single group (normal or rebel workers). This result indicates that in honeybees, there is no trade-off regarding resource allocation between two costly biological functions, learning and reproduction.

\section{SUPPLEMENTARY INFORMATION}

The online version contains supplementary material available at https://doi.org/10.1007 /s13592-021-00847-9.

\section{ACKNOWLEDGEMENTS}

We thank Michał Woyciechowski and two anonymous reviewers for their suggestions and comments.

Data accessibility statement Upon acceptance, the data used in this study will be available in the supplementary data file.

Disclaimer The funders had no role in the study design, data collection and analysis, decision to publish or preparation of the manuscript.

\section{AUTHOR CONTRIBUTIONS}

Conceived of and designed the experiments: K.K. Performed the experiments: K.K., W.R. Analysed the data: K.K. Contributed reagents/materials/analytical tools: K.K. Wrote the paper: K.K., W.R.

\section{Funding}

This study was funded by the National Science Centre (NCN), Poland (grant 2016/23/B/NZ8/ 00803) and Jagiellonian University (grant DS/ BiNoZ/INoŚ/761/18-19). We thank American Journal Experts for language editing (Certificate Verification Key 81C2-143C-3A8F-10BA02BP).

\section{DECLARATIONS}

Competing interests The authors declare that they have no competing interests.

\section{OPEN ACCESS}

This article is licensed under a Creative Commons Attribution 4.0 International License, which permits use, sharing, adaptation, distribution and reproduction in any medium or format, as long as you give appropriate credit to the original author(s) and the source, provide a link to the Creative Commons licence, and indicate if changes were made. The images or other third party material in this article are included in the article's Creative Commons licence, unless indicated otherwise in a credit line to the material. If material is not included in the article's Creative Commons licence and your intended use is not permitted by statutory regulation or exceeds the permitted use, you will need to obtain permission directly from the copyright holder. To view a copy of this licence, visit http://creativecommons. org/licenses/by/4.0/.

Les ouvrières avec un potentiel de reproduction plus élevé ont une plus grande capacité d'apprentissage.

Apis mellifera / abeille domestique / ouvrières rebelles / apprentissage / compromis évolutionniste / reproduction. 
Arbeiterinnen der Honigbiene mit hoher Reproduktonskapazität haben eine bessere Lernfähigkeit.

\section{Apis mellifera / Honigbiene / Rebellenarbeiterinnen / Lernen / evolutiver Trade-off / Reproduktion.}

\section{REFERENCES}

Agarwal, M., Guzmán, M., Morales-Matos, C., Del Valle Díaz, R. A., Abramson, C. I., \& Giray, T. (2011). Dopamine and octopamine influence avoidance learning of honey bees in a place preference assay. PLoS ONE 6 (9), 1-9. https://doi.org/10.1371/journal. pone. 0025371

Alghamdi, A., Raine, N. E., Rosato, E., \& Mallon, E. B. (2009). No evidence for an evolutionary trade-off between learning and immunity in a social insect. Biol. Lett. 5 (1), 55-57. https://doi.org/10.1098 $/$ rsbl.2008.0514

Amdam, G. V., Fennern, E., Baker, N., \& Rascón, B. (2010). Honeybee associative learning performance and metabolic stress resilience are positively associated. PLoS ONE 5(3). https://doi.org/10.1371/journal. pone. 0009740

Beggs, K. T., Glendining, K. A, Marechal, N. M., Vergoz, V., Nakamura, I., Slessor, K. N., \& Mercer, A. R. (2007). Queen pheromone modulates brain dopamine function in worker honey bees. Proc. Natl. Acad. Sci. U. S. A. 104 (7), 2460-2464. https://doi.org/10.1073 /pnas.0608224104

Behrends, A., \& Scheiner, R. (2012). Octopamine improves learning in newly emerged bees but not in old foragers. J. Exp. Biol. 215 (7), 1076-1083. https://doi. org/10.1242/jeb.063297

Beninger, R. J. (1983). The role of dopamine in locomotor activity and learning. Brain Res. Rev. 6(2), 173-196. https://doi.org/10.1016/0165-0173(83)90038-3

Carlsson, A., Lindqvist, M., Magnusson, T., \& Waldeck, B. (1958). On the presence of 3-hydroxytyramine in brain. Science 127, 471 .

Christiansen, I. C., Szin, S., \& Schausberger, P. (2016). Benefit-cost trade-offs of early learning in foraging predatory mites Amblyseius swirskii. Sci. Rep. 6 (March), 1-12. https://doi.org/10.1038 /srep23571

Corona, M., Velarde, R. A, Remolina, S., Moran-Lauter, A., Wang, Y., Hughes, K. A, \& Robinson, G. E. (2007). Vitellogenin, juvenile hormone, insulin signaling, and queen honey bee longevity. Proc. Natl. Acad. Sci. U. S. A. 104 (17), 7128-7133. https://doi. org/10.1073/pnas.0701909104
Dukas, R. (2008). Evolutionary biology of insect learning. Annu. Rev. Entomol. 53, 145-160. https://doi. org/10.1146/annurev.ento.53.103106.093343

Giurfa, M. (2006). Associative learning: the instructive function of biogenic amines. Curr. Biol. 16(20), 892-895. https://doi.org/10.1016/j.cub.2006.09.022

Giurfa, M., \& Sandoz, J. C. (2012). Invertebrate learning and memory: fifty years of olfactory conditioning of the proboscis extension response in honeybees. Learn. Mem. 19(2), 54-66. https://doi.org/10.1101 $/ \operatorname{lm} .024711 .111$

Harano, K. I., Sasaki, K., \& Nagao, T. (2005). Depression of brain dopamine and its metabolite after mating in European honeybee (Apis mellifera) queens. Naturwissenschaften 92 (7), 310-313. https://doi. org/10.1007/s00114-005-0631-3

Harris, J. W., \& Woodring, J. (1995). Elevated brain dopamine levels associated with ovary development in queenless worker honey bees (Apis mellifera L.). Science I (2), 271-279. https://doi.org/10.1016/07428413(95)00048-S

Jaumann, S., Scudelari, R., \& Naug, D. (2013). Energetic cost of learning and memory can cause cognitive impairment in honeybees. Biol. Lett. 9(4). https://doi. org/10.1098/rsbl.2013.0149

Keller, L., \& Genoud, M. (1997). Extraordinary lifespans in ants: a test of evolutionary theories of ageing. Lett. Nat. 389 (October), 958-960. https://doi.org/10.1038 $/ 40130$

Kuszewska, K., \& Woyciechowski, M. (2015). Age at which larvae are orphaned determines their development into typical or rebel workers in the honeybee (Apis mellifera L.). PLoS One 10 (4), e 0123404.

Kuszewska, K., Miler, K., Rojek, W., \& Woyciechowski, M. (2017). Honeybee workers with higher reproductive potential live longer lives. Exp. Gerontol. 98 (June), 8-12. https://doi.org/10.1016/j. exger.2017.08.022

Kuszewska, K., Miler, K., Rojek, W., Ostap-Chęć, M., \& Woyciechowski, M. (2018a). Rebel honeybee workers have a tendency to become intraspecific reproductive parasites. Ecol. Evol. 8(October), 1-7. https://doi. org/10.1002/ece3.4647

Kuszewska, K., Miler, K., \& Woyciechowski, M. (2018b). Honeybee rebel workers invest less in risky foraging than normal workers. Sci. Rep. 8 (July 2017), 9459. https://doi.org/10.1038/s41598-018-27844-w

Kuszewska, K., Wacławska, A., \& Woyciechowski, M. (2018c). Reproduction of rebel workers in honeybee (Apis mellifera) colonies. Apidologie 49, 162-171. https://doi.org/10.1007/s13592-017-0537-z

Kuszewska, K., Miler, K., \& Woyciechowski, M. (2019). Honeybee rebel workers preferentially respond to high concentrations of sucrose. Apidologie 253-261. https://doi.org/10.1007/s13592-019-00641-8

Laughlin, S. B., De Ruyter Van Steveninck, R. R., \& Anderson, J. C. (1998). The metabolic cost of neural information. Nat. Neurosci. 1 (1), 36-41. https://doi. org/10.1038/236 
Leadbeater, E., \& Chittka, L. (2007). Social learning in insects - from miniature brains to consensus building. Curr. Biol. 17 (16), 703-713. https://doi.org/10.1016/j. cub.2007.06.012

Leadbeater, E., \& Dawson, E. H. (2017). A social insect perspective on the evolution of social learning mechanisms. Proc. Natl. Acad. Sci. 114 (30), 7838-7845. https://doi.org/10.1073/pnas.1620744114

Makert, G. R., Paxton, R. J., \& Hartfelder, K. (2006). Ovariole number - a predictor of differential reproductive success among worker subfamilies in queenless honeybee (Apis mellifera L.) colonies. Behav. Ecol. Sociobiol. 60 (6), 815-825. https://doi.org/10.1007 /s00265-006-0225-X

Mancini, N., Giurfa, M., Sandoz, J. C., \& Avarguès-Weber, A. (2018). Aminergic neuromodulation of associative visual learning in harnessed honey bees. Neurobiol. Learn. Mem. 155 (May), 556-567. https://doi. org/10.1016/j.nlm.2018.05.014

Menzel, R., \& Muller, U. (1996). Learning and memory in honeybees: from behavior to neural substrates. Annu. Rev. Neurosci. 19, 379-404. https://doi.org/10.1146 /annurev.neuro.19.1.379

Mery, F., \& Kawecki, T. J. (2003). A fitness cost of learning ability in Drosophila melanogaster. Proc. Biol. Sci. / R. Soc. 270 (1532), 2465-2469. https://doi.org/10.1098/rspb.2003.2548

Mery, F., \& Kawecki, T. J. (2004). An operating cost of learning in Drosophila melanogaster. Anim. Behav. 68 (3), 589-598. https://doi.org/10.1016/j. anbehav.2003.12.005

Mery, F., \& Kawecki, T. J. (2005). A cost of long-term memory in Drosophila. Science (New York, N.Y.) 308(5725), 1148. https://doi.org/10.1126/science.1111331

Miler, K., Kuszewska, K., Zuber, G., \& Woyciechowski, M. (2018a). Larval antlions show a cognitive ability/ hunting efficiency trade-off connected with the level of behavioural asymmetry. Anim. Cogn. 21 (4), 613-617. https://doi.org/10.1007/s10071-018-1190-2

Miler, K., Kuszewska, K., Zuber, G., \& Woyciechowski, M. (2018b). Larval antlions show a cognitive ability/ hunting efficiency trade-off connected with the level of behavioural asymmetry. Anim. Cogn. https://doi. org/10.1007/s10071-018-1190-2

Nakaoka, T., Takeuchi, H., \& Kubo, T. (2008). Laying workers in queenless honeybee (Apis mellifera L.) colonies have physiological states similar to that of nurse bees but opposite that of foragers. J. Insect Physiol. 54 (5), 806-812. https://doi.org/10.1016/j. jinsphys.2008.02.007

Parker, J. D. (2010). What are social insects telling us about aging? Myrmecol. News 13 (April), 103-110.

Paul, G., Philippides, A., \& Baddeley, B. (2010). Animal cognition: multi-modal interactions in ant learning. Curr. Biol. 15(20), R639-R640.

Raine, N. E., \& Chittka, L. (2012). No trade-off between learning speed and associative flexibility in bumblebees: a reversal learning test with multiple colonies.
PLoS ONE 7 (9). https://doi.org/10.1371/journal. pone. 0045096

Ratnieks, F. L. W., \& Visscher, P. K. (1989). Worker policing in the honeybee. Nature 342, 796-797.

Reznick, D., Nunney, L., \& Tessier, A. (2000). Big houses, big cars, superfleas and the costs of reproduction. Trends Ecol. Evol. 15(10), 421-425. https://doi. org/10.1016/S0169-5347(00)01941-8

Sasaki, K., Matsuyama, S., Harano, Kichi, \& Nagao, T. (2012). Caste differences in dopamine-related substances and dopamine supply in the brains of honeybees (Apis mellifera L.). Gen. Comp. Endocrinol. 178 (1), 46-53. https://doi.org/10.1016/j. ygcen.2012.04.006

Scheiner, R., Plückhahn, S., Öney, B., Blenau, W., \& Erber, J. (2002). Behavioural pharmacology of octopamine, tyramine and dopamine in honey bees. Behav. Brain Res. 136 (2), 545-553. https://doi. org/10.1016/S0166-4328(02)00205-X

Scheiner, R., Baumann, A., \& Blenau, W. (2006). Aminergic control and modulation of honeybee behaviour. Curr. Neuropharmacol. 4 (4), 259-276. https://doi.org/10.2174/157015906778520791

Scheiner, R., Abramson, C. I., Brodschneider, R., Crailsheim, K., Farina, W. M., Fuchs, S., ... Thenius, R. (2013). Standard methods for behavioural studies of Apis mellifera. J. Apicult Res. 52 (4), 1-58. https://doi. org/10.3896/IBRA.1.52.4.04

Snell-Rood, E. C., Papaj, D. R., \& Gronenberg, W. (2009). Brain size: a global or induced cost of learning? Brain Behav. Evol. 73 (2), 111-128. https://doi.org/10.1159 /000213647

Snell-Rood, E. C., Davidowitz, G., \& Papaj, D. R. (2011). Reproductive tradeoffs of learning in a butterfly. Behav. Ecol. 22 (2), 291-302. https://doi.org/10.1093 /beheco/arq169

Spivak, M., Masterman, R., Ross, R., \& Mesce, K. A. (2003). Hygienic behavior in the honey bee (Apis mellifera L.) and the modulatory role of octopamine. J. Neurobiol. 55 (3), 341-354. https://doi.org/10.1002 /neu.10219

Swevers, L., Raikhel, A. S., Sappington, T. W., Shirk, P. D., \& Iatrou, K. (2005). Vitellogenesis and postvitellogenic maturation of the insect ovarian follicle. In: L. Gilbert, K. Iatrou, \& S. Gill (Eds.), Comprehensive molecular insect science, volume 1 (pp. 87-155). New York: Elsevier Pergamon. Retrieved from http://agris.fao.org/agris-search/search.do?recordID= US201300837871

Taylor, D. J., Robinson, G. E., Logan, B. J., Laverty, R., \& Mercer, A. R. (1992). Changes in brain amine levels associated with the morphological and behavioural development of the worker honeybee. J. Comp. Physiol. A. 170 (6), 715-721. https://doi.org/10.1007 /BF00198982

Thompson, R. F. (1986). The neurobiology of learning and memory. Science 233 (4767), 941-947.

Vergoz, V., Roussel, E., Sandoz, J. C., \& Giurfa, M. (2007). Aversive learning in honeybees revealed by 
the olfactory conditioning of the sting extension reflex. PLoS ONE 2(3). https://doi.org/10.1371/journal. pone. 0000288

Winston, M. (1987). The biology of honeybee. Cambridge, Massachusetts: Harvard University Press.

Woyciechowski, M., \& Kuszewska, K. (2012). Swarming generates rebel workers in honeybees. Curr. Biol. $22(8), 707-711$. https://doi.org/10.1016/j. cub.2012.02.063

Woyciechowski, M., \& Lomnicki, A. (1987). Multiple mating of queens and the sterility of workers among eusocial Hymenoptera. J. Theor. Biol. 128, 317-327.
Woyciechowski, M., Kuszewska, K., Pitorak, J., \& Kierat, J. (2017). Honeybee worker larvae perceive queen pheromones in their food. Apidologie 48, 144-149. https://doi.org/10.1007/s1359201604591

Woyke, J. (1999). Increased food supply to all larvae after dequeening honey bee colonies. J. Apic. Res. 38, $117-$ 123.

Publisher's note Springer Nature remains neutral with regard to jurisdictional claims in published maps and institutional affiliations. 